\title{
Conhecimento de acadêmicos de enfermagem sobre a vacina contra o papilomavirus humano
} Nursing students' knowledge on the human papillomavirus vaccine Conocimientos de académicos de enfermería sobre la vacuna contra el virus del papiloma humano

Marislei Sanches Panobianco ${ }^{1}$ @ https://orid.org/0000-0003-2619-8740

Amanda Vieira Bezerril2 Ee https://orcid.org/0000-0003-1455-2327

Larissa Clara Nunes ${ }^{1}$ id https://orcid.orgy/0000-0002-9687-7127

Ana Paula Alonso Reis Mairink ${ }^{1}$ ic nttps://orcid.org/0000-0001-9812-9344

Thais de Oliveira Gozzo' 1 on htps://orcid.org/0000-0002-7687-9459

Ana Carolina Sipoli Canete ${ }^{1}$ io https://orcid.org/0000-0002-2131-0249

Andrea Ferreira Ouchi França ${ }^{3}$ io https://orcid.org//0000-0002-0024-6428

Como citar:

Panobianco MS, Bezerril AV, Nunes LC, Mairink

AP, Gozzo TO, Canete AC, et al. Conhecimento

de acadêmicos de enfermagem sobre a vacina contra o papilomavirus humano. Acta Paul Enferm.
2022;35:eAPE02291.

DOI

http://dx.doi.org/10.37689/acta-ape/2022A002291

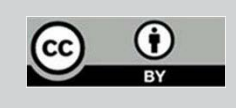

Descritores

Estudantes de enfermagem; Papilomavírus humano; Imunização; Conhecimento

Keywords

Nursing students; Human papillomavirus; Immunization; Knowledge

Descriptores

Estudiantes de enfermeira; infecciones por papillomavirus; Inmunización; Conocimiento

Submetido 23 de Agosto de 2020

Aceito

23 de Março de 2021

Autor correspondente

Marislei Sanches Panobianco

E-mail: marislei@eerp.usp.br

Editor Associado (Avaliação pelos pares): (https://orcid.org/0000-0002-1408-196X) Escola Paulista de Enfermagem, Universidade Federal de São Paulo, São Paulo, SP, Brasil

\section{Resumo}

Objetivo: Avaliar o conhecimento entre acadêmicos de enfermagem sobre a vacina contra o papilomavírus humano e comparar os resultados obtidos entre estudantes do primeiro e do último ano de graduação.

Métodos: Estudo descritivo, transversal, quantitativo, realizado entre maio e junho de 2019. Aplicado questionário a 179 estudantes do curso de Enfermagem de uma universidade pública do estado de São Paulo, contendo dados sociodemográficos e outro sobre o conhecimento do papilomavírus humano e a vacina contra o mesmo. Dados foram analisados através do programa Statistical Packcage for Social Science.

Resultados: 82,4\% dos estudantes do primeiro ano e 95,5\% do último responderam que sabiam o que é 0 papilomavírus humano, e afirmaram ser um vírus sexualmente transmissível. Lacunas de conhecimento foram identificadas, quanto à finalidade do exame citopatológico, aos fatores de risco relacionados à infecção e relacionados à vacina, como número de doses e possíveis riscos e benefícios da mesma.

Conclusão: Apesar de os acadêmicos demonstrarem conhecimento quanto ao papilomavírus humano, sua transmissibilidade e relação direta com o câncer do colo do útero, ainda apresentaram dúvidas importantes que devem ser sanadas, quanto à finalidade do exame citopatológico, aos fatores de risco para infecção pelo vírus e em relação à vacina contra o papilomavírus humano.

\section{Abstract}

Objective: To assess nursing students' knowledge on the human papillomavirus vaccine and compare the results obtained among students of the first and last year of graduation.

Methods: This is a descriptive, cross-sectional, quantitative study, conducted between May and June 2019. A questionnaire was applied to 179 nursing students from a public university in the state of São Paulo, containing sociodemographic data and another on knowledge of human papillomavirus and the vaccine against it. Data were analyzed using the Statistical Packcage for Social Science.

Results: $82.4 \%$ of first-year students and $95.5 \%$ of last-year students answered that they knew what human papillomavirus is, claiming to be a sexually transmitted virus. Knowledge gaps were identified regarding the purpose of cytopathological examination, risk factors related to infection and related to the vaccine, such as number of doses and possible risks and benefits of it.

Conclusion: Although students demonstrated knowledge on human papillomavirus, its transmissibility and direct relationship with cervical cancer, they still presented important doubts that should be answered, regarding the purpose of the cytopathological examination, the risk factors for infection by the virus and in relation to the vaccine against the human papillomavirus.

'Escola de Enfermagem de Ribeirão Preto, Universidade de São Paulo, Ribeirão Preto, SP, Brasil.

2Escola de Enfermagem, Universidade de São Paulo, de São Paulo, São Paulo, SP, Brasil.

3Universidade do Oeste do Paraná, Foz do Iguaçu, PR, Brasil.

Conflitos de interesse: nada a declarar. 


\section{Resumen}

Objetivo: Evaluar los conocimientos de académicos de enfermería sobre la vacuna contra el virus del papiloma humano y comparar los resultados obtenidos de estudiantes del primer y del último año de carrera.

Métodos: Estudio descriptivo, transversal, cuantitativo realizado entre mayo y junio de 2019. Cuestionario aplicado a 179 estudiantes de la carrera de Enfermería de una universidad pública del estado de São Paulo, que contenía datos sociodemográficos, y otro sobre conocimientos del virus del papiloma humano y su vacuna. Los datos fueron analizados a través del programa Statistical Packcage for Social Science.

Resultados: El 82,4 \% de los estudiantes de primer año y el 95,5 \% del último respondieron que sabían lo que es el virus del papiloma humano y afirmaron que es un virus sexualmente transmisible. Se identificaron vacíos de conocimiento respecto a la finalidad del estudio citológico, a los factores de riesgo relacionados con la infección y con la vacuna, como número de dosis y sus posibles riesgos y beneficios.

Conclusión: A pesar de que los académicos demostraron conocimientos respecto al virus del papiloma humano, su transmisión y relación directa con el cáncer de cuello uterino, también presentaron dudas importantes que deben ser aclaradas sobre la finalidad del estudio citológico, los factores de riesgo de la infección por el virus y sobre la vacuna contra el virus del papiloma humano.

\section{Introdução}

O câncer do colo do útero (CCU) mata 250 mil mulheres anualmente, no mundo, sendo $85 \%$ dos óbitos em países de baixa e média renda, como afirma a Agência Internacional de Pesquisa em Câncer (IARC) da Organização Mundial da Saúde (OMS). ${ }^{(1)}$

No Brasil, estima-se que, para cada ano do triênio 2020-2022, ocorram 16.590 casos novos de CCU; considerada a quarta causa de morte de mulheres por câncer e o quarto tumor mais frequente na população feminina. ${ }^{(2)}$

Este tumor se desenvolve a partir de alteraçóes do epitélio do colo do útero (lesôes precursoras), muitas vezes causadas pelo papilomavírus humano (HPV). ${ }^{(3,4)}$ Dentre as centenas de HPV conhecidos, são considerados de alto risco oncogênico, os genótipos 16 e 18; além de outros fatores associados como: início precoce da atividade sexual, imunossupressão, multiparidade. ${ }^{(5)}$ Dentre os tipos de baixo risco, os 6 e 11 são os mais detectados em lesóes de condiloma acuminado. ${ }^{(6)}$

Sua principal estratégia de rastreamento é a realização periódica do exame citopatológico, que mostra resultados reconhecidos pelo Instituto Nacional de Câncer (INCA), identificando até 90\% dos casos, mesmo antes da manifestação de sintomas, com diminuição da mortalidade em até $50 \%$. ${ }^{(7)} \mathrm{O}$ exame é preconizado para mulheres entre 25 e 64 anos que já iniciaram atividade sexual, sendo recomendada sua realização uma vez por ano e, após dois exames anuais consecutivos negativos, a cada três anos. ${ }^{\left({ }^{(8)}\right.}$

Em relação à prevenção da doença, estudo em que foram entrevistados 10 enfermeiros que atuam em equipes de Estratégia Saúde da Família (ESF), constatou que a promoção da saúde e a prevenção do CCU acontecem por meio de orientaçóes, aconselhamentos, questionamentos, explicações, visita domiciliar, formação de grupos, educação em saúde em sala de espera. Dessa forma, as açóes educativas sobre a temática favorecem valorização do exame por parte das mulheres, o que interfere na cobertura de realização do exame preventivo. ${ }^{(9)}$

O enfermeiro é um elemento chave no combate ao CCU, cabendo a ele a realização de açóes educativas, consultas, solicitação de exames de rotina, orientaçóes, visitas domiciliares e ainda orientação quanto ao uso de contraceptivos. ${ }^{(10)}$

No entanto, o CCU ainda é considerado um importante problema de saúde pública nos países em desenvolvimento, sendo recomendado que estes invistam na vacinação contra o HPV de crianças e adolescente. $^{(1)}$

Desde 2014, o Ministério da Saúde (MS) brasileiro disponibiliza pelo Sistema Único de Saúde (SUS), a vacina quadrivalente contra o HPV, que promove proteção contra genótipos de baixo e alto risco. Atualmente, a população alvo da vacinação são meninas de nove a 14 anos e meninos de 11 a 14 anos, ambos recebendo duas doses da vacina, com intervalo de seis meses entre elas. ${ }^{(11)}$ Portadores do HIV, de nove a 26 anos. $^{(11)}$

Atualmente a vacina é a principal forma de prevenção do CCU, sendo meta do MS vacinar pelo menos $80 \%$ da população alvo para reduzir a incidência desse câncer nas próximas décadas. A vacinação, em conjunto com o exame citopatológico, complementam-se como açóes preventivas. ${ }^{(12)}$ 
Como a vacina ainda é relativamente nova no país, foram observadas lacunas na literatura quanto à temática, como, por exemplo, a investigação do conhecimento de acadêmicos de cursos da área da saúde sobre a vacina contra o HPV e assuntos relacionados a ela. Além disso, destaca-se a importância da atuação do enfermeiro, no combate ao HPV e suas complicaçóes.

Diante do exposto, o objetivo do estudo foi avaliar o conhecimento dos acadêmicos de enfermagem sobre a vacina contra HPV e comparar os resultados obtidos entre os estudantes do primeiro e do último ano de graduação. $\mathrm{O}$ intuito da comparação foi identificar se aqueles que já tiveram contato com conteúdo sobre a prevenção do CCU apresentam maior conhecimento sobre a vacina contra o HPV.

\section{Métodos}

Estudo descritivo, transversal com abordagem metodológica quantitativa, realizado com universitários do curso de enfermagem de uma Instituição de Ensino Superior (IES) pública do interior do estado de São Paulo. Critérios de inclusão: estudantes de ambos os sexos, idade igual ou superior a 18 que estavam frequentando o primeiro ou o último ano dos cursos de Bacharelado e de Bacharelado e Licenciatura em Enfermagem, no ano de 2019.

Considerou-se uma amostragem por conveniência e a coleta de dados deu-se entre maio e junho de 2019. O convite foi realizado em sala de aula, com apresentação da pesquisa, além do esclarecimento de dúvidas. Aqueles que aceitaram participar assinaram o Termo de Consentimento Livre e Esclarecido e responderam um instrumento contendo dados sociodemográficos e outro sobre o conhecimento dos participantes a respeito do HPV e a vacina contra o mesmo. Participaram 179 estudantes do curso de Enfermagem de uma universidade pública do estado de São Paulo.

Para a coleta dos dados foi utilizado um instrumento nacional previamente validado, ${ }^{(13)}$ o qual contém dados de identificação do participante e seis domínios, totalizando 31 perguntas. $\mathrm{O}$ primeiro domínio aborda o conhecimento sobre o HPV; o segundo, o conhecimento sobre a vacina; o terceiro aborda as barreiras para a vacinação; o quarto, a aceitabilidade da vacina; o quinto, os antecedentes pessoais, direcionado às participantes do sexo feminino, e o sexto, e último, para profissionais da saúde. ${ }^{(13)}$ Para esta pesquisa, não foram utilizados os dois últimos domínios do instrumento.

Os dados coletados foram tabulados por dupla digitação e posterior validação, utilizando-se o Microsoft Excel 2010. Utilizou-se o programa Statistical Packcage for Social Science (SPSS) versão 25. A análise dos dados deu-se por meio de estatística descritiva, utilizando-se de técnicas que resultaram em tabelas de frequência para as variáveis quantitativas e qualitativas.

A pesquisa seguiu os termos da Resolução no 466/2012 e foi autorizada pelo Comitê de Ética em Pesquisa da instituição, sob o número de parecer $n^{\circ}$ 3.178.962.

\section{Resultados}

Foram incluídos 179 estudantes regularmente matriculados, sendo que $62,0 \%$ cursavam bacharelado e 38,0\% bacharelado e licenciatura. Ainda, 50,8\% eram estudantes do primeiro ano, e 49,2\% do último ano.

A idade dos participantes variou entre 18 e 38 anos, com média de 21,5 anos $(\mathrm{DP}=2,96), 85,5 \%$ do sexo feminino, 77,7\% autodeclaravam-se brancos, $95,5 \%$ solteiros e 43,0\% católicos. Quanto à renda, $75,4 \%$ responderam ter renda até cinco salários mínimos. A maioria $(58,1 \%)$ era procedente do estado de São Paulo.

$\mathrm{O}$ primeiro domínio aborda o conhecimento sobre o HPV e $82,4 \%$ dos estudantes do primeiro e $95,5 \%$ do último ano tanto afirmaram saber, como responderam acertadamente que se trata de um vírus (86,8\% e $97,7 \%$ respectivamente). Reconheceram o HPV como uma infecção sexualmente transmissível (IST), podendo desenvolver CCU (Tabela 1).

$\mathrm{Na}$ pergunta cinco, 33\% dos participantes do primeiro ano não sabiam que o HPV pode causar alteraçóes no exame citopatológico. Dúvidas também foram observadas na sexta pergunta em que 
$41,8 \%$ não sabiam ou não tinham certeza de que o HPV é uma das principais causas de câncer em mulheres. Nas respostas da pergunta sete, observam-se dúvidas quanto ao uso do fumo aumentar o risco de CCU ente as mulheres, tanto entre os estudantes de primeiro quanto do último ano $(76,9 \%$ e $28,4 \%$, respectivamente) (Tabela 1 ).

Tabela 1. Distribuição de frequência das respostas entre estudantes do primeiro $(\mathrm{n}=91)$ e último $(\mathrm{n}=88)$ períodos quanto ao primeiro domínio do questionário "Conhecimento sobre o HPV"

\begin{tabular}{|c|c|c|}
\hline Distribuição de frequência das respostas entre estudantes & $\begin{array}{c}\text { Primeiro } \\
\text { ano } \\
\mathrm{n}(\%)\end{array}$ & $\begin{array}{l}\text { Último } \\
\text { ano } \\
\text { n(\%) }\end{array}$ \\
\hline \multicolumn{3}{|l|}{ 1. Você sabe o que é o HPV? } \\
\hline Sim & $75(82,4)$ & $84(95,5)$ \\
\hline Não tenho certeza & $16(17,6)$ & $4(4,5)$ \\
\hline Total & $91(100)$ & $88(100)$ \\
\hline \multicolumn{3}{|l|}{ 2.0 HPV é um vírus? } \\
\hline Sim & $79(86,8)$ & $86(97,7)$ \\
\hline Não & $2(2,2)$ & $1(1,1)$ \\
\hline Não tenho certeza & $10(11,0)$ & $1(1,1)$ \\
\hline Total & $91(100,0)$ & $88(100,0)$ \\
\hline \multicolumn{3}{|l|}{ 3.0 HPV é uma infecção sexualmente transmissível? } \\
\hline Sim & $82(90,1)$ & $84(95,5)$ \\
\hline Não & $3(3,3)$ & $1(1,1)$ \\
\hline Não tenho certeza & $6(6,6)$ & $3(3,4)$ \\
\hline Total & $91(100,0)$ & $88(100,0)$ \\
\hline \multicolumn{3}{|l|}{ 4. 0 HPV pode causar câncer de colo do útero? } \\
\hline $\operatorname{Sim}$ & $83(91,2)$ & $87(98,9)$ \\
\hline Não & - & $1(1,1)$ \\
\hline Não tenho certeza & $8(8,8)$ & - \\
\hline Total & $91(100,0)$ & $88(100,0)$ \\
\hline \multicolumn{3}{|l|}{$\begin{array}{l}\text { 5. } 0 \text { HPV pode causar alterações no Papanicolau (exame } \\
\text { preventivo de câncer de colo do útero)? }\end{array}$} \\
\hline $\operatorname{Sim}$ & $61(67,0)$ & $81(92,0)$ \\
\hline Não & - & $1(1,1)$ \\
\hline Não tenho certeza & $30(33,0)$ & $6(6,8)$ \\
\hline Total & $91(100,0)$ & $88(100,0)$ \\
\hline \multicolumn{3}{|l|}{ 6. O HPV é uma das principais causas de câncer em mulheres? } \\
\hline Sim & $53(58,2)$ & $81(92,0)$ \\
\hline Não & $8(8,8)$ & $6(6,8)$ \\
\hline Não tenho certeza & $30(33,0)$ & $1(1,1)$ \\
\hline Total & $91(100,0)$ & $88(100,0)$ \\
\hline \multicolumn{3}{|l|}{ 7. Fumar pode aumentar o risco de câncer colo do útero? } \\
\hline Sim & $21(23,1)$ & $61(69,3)$ \\
\hline Não & $11(12,1)$ & $8(9,1)$ \\
\hline Não tenho certeza & $59(64,8)$ & $17(19,3)$ \\
\hline Total & $91(100,0)$ & $86(97,7)$ \\
\hline
\end{tabular}

O segundo domínio trouxe questóes que exploraram o conhecimento sobre a vacina contra o HPV (Tabela 2). Neste, observaram-se dúvidas entre os participantes do primeiro e último ano, quando questionado sobre a aplicação da vacina em pessoas sexualmente ativas ( $41,8 \%$ e $31,9 \%$, respectivamente). Destaca-se também a incerteza destes quanto ao número de doses da vacina $(84,7 \%$ e $78,4 \%$, respectivamente). Ainda, sobre a vacina reduzir as chances do desenvolvimento do condiloma acuminado, $44 \%$ do primeiro ano e $42,1 \%$ do último ano não souberam responder acertadamente (Tabela 2).

Tabela 2. Distribuição de frequência das respostas entre estudantes do primeiro e último períodos quanto ao segundo domínio do questionário "Conhecimento sobre a vacina contra HPV"

\begin{tabular}{|c|c|c|}
\hline Distribuição de frequência das respostas entre estudantes & \multirow[t]{2}{*}{$\begin{array}{c}\text { Primeiro } \\
\text { ano } \\
\mathrm{n}(\%)\end{array}$} & \multirow[t]{2}{*}{$\begin{array}{l}\text { Último } \\
\text { ano } \\
\mathrm{n}(\%)\end{array}$} \\
\hline 1. A vacina contra HPV previne o câncer de colo de útero? & & \\
\hline Sim & $65(71,4)$ & $70(79,3)$ \\
\hline Não & $10(11,0)$ & $14(15,9)$ \\
\hline Não tenho certeza & $15(16,5)$ & $4(4,5)$ \\
\hline Total & $90(98,8)$ & $88(100,0)$ \\
\hline $\begin{array}{l}\text { 2. A vacina contra HPV deve ser aplicada antes da primeira } \\
\text { relação sexual? }\end{array}$ & & \\
\hline Sim & $57(62,6)$ & $71(80,7)$ \\
\hline Não & $12(13,2)$ & $9(10,2)$ \\
\hline Não tenho certeza & $22(24,2)$ & $8(9,1)$ \\
\hline Total & $91(100,0)$ & $88(100,0)$ \\
\hline $\begin{array}{l}\text { 3. A vacina contra HPV pode ser aplicada em quem já teve } \\
\text { relação sexual? }\end{array}$ & & \\
\hline Sim & $53(58,2)$ & $60(68,2)$ \\
\hline Não & $9(9,9)$ & 10(11.4) \\
\hline Não tenho certeza & $29(31,9)$ & $18(20,5)$ \\
\hline Total & $91(100,0)$ & $88(100,0)$ \\
\hline 4. A vacina contra HPV pode ser prejudicial a saúde? & & \\
\hline Sim & $1(1,1)$ & $2(2,3)$ \\
\hline Não & $75(82,4)$ & $81(92,0)$ \\
\hline Não tenho certeza & $15(16,5)$ & $5(5,7)$ \\
\hline Total & $91(100,0)$ & $88(100,0)$ \\
\hline 5. A vacina contra HPV pode causar infecção por HPV? & & \\
\hline Sim & $3(3,3)$ & $5(5,7)$ \\
\hline Não & $67(73,6)$ & $71(80,7)$ \\
\hline Não tenho certeza & $21(23,1)$ & $12(13,6)$ \\
\hline Total & $91(100,0)$ & $88(100,0)$ \\
\hline 6. A vacina contra HPV é fornecida pelo Governo? & & \\
\hline Sim & $83(91,2)$ & $88(100,0)$ \\
\hline Não & $4(4,4)$ & - \\
\hline Não tenho certeza & $4(4,4)$ & - \\
\hline Total & $91(100,0)$ & $88(100,0)$ \\
\hline $\begin{array}{l}\text { 7. A vacina contra HPV faz parte da carteirinha de vacinaçãa das } \\
\text { meninas? }\end{array}$ & & \\
\hline Sim & $57(62,6)$ & $77(87,5)$ \\
\hline Não & $10(11,0)$ & $3(3,4)$ \\
\hline Não tenho certeza & $24(26,4)$ & $8(9,1)$ \\
\hline Total & $91(100,0)$ & $88(100,0)$ \\
\hline 15.1. Ficou sabendo sobre a vacina contra HPV pela escola & & \\
\hline Sim & $41(45,1)$ & $49(55,7)$ \\
\hline Não & $49(53,8)$ & $39(44,3)$ \\
\hline Total & $90(98,9)$ & $88(100,0)$ \\
\hline 15.2. Ficou sabendo sobre a vacina contra HPV pelos amigos & & \\
\hline Sim & $7(7,7)$ & $11(12,5)$ \\
\hline Não & $83(91,2)$ & $77(87,5)$ \\
\hline Total & $90(98,9)$ & $88(100,0)$ \\
\hline
\end{tabular}




\begin{tabular}{|c|c|c|}
\hline Distribuição de frequência das respostas entre estudantes & $\begin{array}{c}\text { Primeiro } \\
\text { ano } \\
\mathrm{n}(\%)\end{array}$ & $\begin{array}{l}\text { Último } \\
\text { ano } \\
\text { n(\%) }\end{array}$ \\
\hline \multicolumn{3}{|l|}{ 15.3. Ficou sabendo sobre a vacina pela TV/rádio } \\
\hline Sim & $16(17,6)$ & $21(23,9)$ \\
\hline Não & $74(81,3)$ & $67(76,1)$ \\
\hline Total & $90(98,9)$ & $88(100,0)$ \\
\hline \multicolumn{3}{|l|}{ 15.4. Ficou sabendo sobre a vacina contra HPV pela internet } \\
\hline Sim & $11(12,1)$ & $32(36,4)$ \\
\hline Não & $79(86.8)$ & $56(63,6)$ \\
\hline Total & $90(98,9)$ & $88(100,0)$ \\
\hline \multicolumn{3}{|l|}{$\begin{array}{l}\text { 15.5. Ficou sabendo sobre a vacina contra HPV por profissional } \\
\text { de saúde }\end{array}$} \\
\hline $\operatorname{Sim}$ & $31(34,1)$ & $41(46,6)$ \\
\hline Não & $59(64,8)$ & $47(53,4)$ \\
\hline Total & $90(98,9)$ & $88(100,0)$ \\
\hline \multicolumn{3}{|l|}{ 15.6. Ficou sabendo sobre a vacina contra HPV por outros meios } \\
\hline Sim & $6(6,6)$ & $9(10,2)$ \\
\hline Não & $84(92,3)$ & $79(89.8)$ \\
\hline Total & $90(98.9)$ & $88(100,0)$ \\
\hline \multicolumn{3}{|l|}{ 16. São necessárias 3 doses para vacinação completa? } \\
\hline Sim & $38(41,8)$ & $42(47,7)$ \\
\hline Não & $14(15,4)$ & $19(21,6)$ \\
\hline Não tenho certeza & $39(42,9)$ & $27(30,7)$ \\
\hline Total & $91(100,0)$ & $88(100,0)$ \\
\hline \multicolumn{3}{|l|}{$\begin{array}{l}\text { 17. A vacina contra HPV diminui a chance de ter verrugas } \\
\text { genitais? }\end{array}$} \\
\hline Sim & $51(56,0)$ & $51(58,0)$ \\
\hline Não & $4(4,4)$ & $16(18,2)$ \\
\hline Não tenho certeza & $36(39,6)$ & $21(23,9)$ \\
\hline Total & $91(100,0)$ & $88(100,0)$ \\
\hline
\end{tabular}

O terceiro domínio procurou identificar as barreiras para a vacinação, merecendo destaque, pois $100,0 \%$ dos participantes, dos dois períodos, referiam saber da necessidade de usar o preservativo e identificaram a importância da realização do exame citopatológico, mesmo após a vacinação. Entretanto, 29,6\% do primeiro ano e 33\% do último não souberam responder quais os benefícios da vacina sobre as alteraçóes citológicas (Tabela 3).

Já o quarto domínio contemplou a aceitabilidade da vacina entre os participantes (Tabela 3), e a maioria dos estudantes dos períodos pesquisados recomendou a vacinação. Apesar disso, 41,8\% do primeiro ano e $84,1 \%$ do último ano afirmam que não foram vacinados.

\section{Discussão}

A vacinação contra o HPV vem sendo largamente discutida no mundo e, atualmente no Brasil, desde sua introdução no Calendário Nacional de Vacinação (CNV).
Tabela 3. Distribuição de frequência das respostas entre estudantes do primeiro e último períodos quanto ao quarto domínio do questionário "A aceitabilidade da vacina contra HPV"

\begin{tabular}{l|c|c}
\hline $\begin{array}{l}\text { Distribuição de frequência das respostas entre } \\
\text { estudantes }\end{array}$ & $\begin{array}{c}\text { Primeiro } \\
\text { ano } \\
\mathbf{n}(\%)\end{array}$ & $\begin{array}{c}\text { Último } \\
\text { ano } \\
\mathbf{n}(\%)\end{array}$ \\
\hline 22. Você conhece alguém que já tomou a vacina contra HPV? & & \\
Sim & $77(84,6)$ & $64(72,7)$ \\
Não & $12(13,2)$ & $21(23,9)$ \\
Não tenho certeza & $2(2,2)$ & $3(3,4)$ \\
Total & $91(100,0)$ & $88(100,0)$ \\
23. Você já tomou a vacina contra HPV? & & \\
Não & $38(41,8)$ & $74(84,1)$ \\
Sim/Rede pública & $39(42,9)$ & $7(8,0)$ \\
Sim/Particular & $4(4,4)$ & $5(5,7)$ \\
Sim/Não tenho certeza & $9(9,9)$ & $2(2,3)$ \\
Total & $90(98,9)$ & $88(100,0)$ \\
24. Você recomendaria a vacina contra HPV para filho(a), amigo ou & & \\
parente tomar? & & \\
Sim & $89(97,8)$ & $88(100,0)$ \\
Não tenho certeza & $1(1,1)$ & - \\
Total & $90(98,9)$ & $88(100,0)$ \\
\hline
\end{tabular}

Além disso, outros dados obtidos do perfil sociodemográfico corroboram os de outras pesquisas de mesma temática, como o predomínio de participantes solteiros e jovens, também destaca-se a importância do perfil estudado, pois o mesmo relaciona-se com os casos de CCU secundário à infecção pelo $\mathrm{HPV}^{(14-17)}$

Quanto ao conhecimento sobre o HPV, tanto os estudantes do primeiro ano quanto do último, obtiveram resultados satisfatórios para as primeiras perguntas e os dados corroboram os da pesquisa realizada com estudantes de medicina em Goiás, em que $98-99,4 \%$ dos participantes afirmaram já terem ouvido falar sobre o HPV e o reconhecem como uma IST. ${ }^{(18)}$ Esse é um resultado importante, pois pode tê-los alertado, mesmo que discretamente, quanto a um risco à saúde apresentado pelo HPV.

Apesar de os primeiros resultados terem sido satisfatórios, a pergunta sobre "O HPV pode causar alteraçóes no Papanicolau?” gerou dúvidas, principalmente entre os estudantes do primeiro ano, o que não condiz com as respostas obtidas na pergunta anterior "O HPV pode causar câncer de colo do útero?”, quando a maioria destes estudantes respondeu afirmativamente. A comparação entre as respostas dessas perguntas pode sugerir que os estudantes do primeiro ano talvez ainda não conheçam a finalidade do exame citopatológico. Dado que difere de 
estudo realizado com acadêmicos de enfermagem na Paraíba, revelando que 100,0\% dos participantes afirmaram que o exame citopatológico é eficiente tanto para detecção precoce de CCU quanto para diagnóstico de vulvovaginites. ${ }^{(17)}$

Quando questionados se o CCU é uma das principais causas de câncer em mulheres, também houve dúvidas entre os estudantes do primeiro ano, reforçando a necessidade do preenchimento de lacunas de conhecimento entre os estudantes quanto ao HPV e ao CCU, visto que este acomete uma grande porcentagem de mulheres no país. ${ }^{(19)}$

Sobre a relação do fumo e os riscos de desenvolver o CCU, observaram-se dúvidas entre os alunos do primeiro, sugerindo um déficit de conhecimento quanto aos fatores de risco que predispóem ao CCU. A relação entre o tabagismo e a infecção por HPV, explica-se pela imunossupressão local ocasionada pelo fumo que permite a penetração do vírus nas células com maior facilidade. ${ }^{(20)}$

Sobre a pergunta "A vacina contra o HPV pode ser aplicada em quem já teve relação sexual?", obteve-se número menor de acertos entre os dois períodos. Em pesquisa realizada com adolescentes no Acre, a maioria dos participantes não sabia que a vacina poderia ser aplicada em pessoas que já iniciaram a vida sexual. ${ }^{(21)}$ Após o início da atividade sexual, o risco de contato com o HPV pode aumentar progressivamente, cerca de $25 \%$ das adolescentes apresentam a infecção ainda no primeiro ano do início da atividade sexual, tendo um aumento do percentual em até $70 \%$ três anos após. ${ }^{(22)}$ Até o momento não há evidências que tragam a vacinação como um benefício significativo a mulheres previamente expostas ao vírus, ou seja, algumas podem se beneficiar e outras não. Ressalta-se que a vacina não apresenta riscos caso o indivíduo tenha tido contato prévio com o vírus. ${ }^{(22)}$

Quanto à forma como conheceram a vacina, houve um consenso entre os estudantes de ambos os períodos, sendo os meios mais citados, a escola e profissionais da saúde. Ressalta-se assim, a importância do enfermeiro, profissional capacitado para atuar no processo educativo em saúde nas escolas, pois de acordo com o Programa Saúde na Escola criado em 2007 pelo Ministério da Saúde e Ministério da Educação, por meio do Decreto Presidencial no 6.286, a escola é um espaço que favorece as práticas de promoção à saúde, informações e orientaçôes pertinentes aos serviços de saúde disponíveis. ${ }^{(23,24)}$ Esse achado corrobora os de outro estudo, no qual a maioria dos participantes indicou o enfermeiro e as escolas como principais veículos de informação sobre a vacina, podendo-se afirmar que é fundamental que o enfermeiro seja capacitado para orientar a população adequadamente. ${ }^{(21)}$

A questão quanto ao número de doses da vacina também gerou muitas dúvidas entre os estudantes, dificuldade corroborada por estudo realizado em uma IES de São Paulo com acadêmicos de enfermagem, no qual somente $40 \%$ dos entrevistados responderam corretamente ao número de doses, e um número ainda menor $(15,0 \%)$ soube dizer o intervalo entre elas. ${ }^{(16)}$ Atualmente, tanto para meninas, quanto para meninos, a vacina deve ser aplicada em duas doses injetáveis, sendo a segunda seis meses após a primeira. ${ }^{(11)}$

A totalidade dos alunos dos períodos estudados afirmou que é necessário utilizar preservativo após a vacinação, coincidindo com os outros resultados, quando 99,0\% dos participantes também indicaram tal necessidade. ${ }^{(16)}$ Desta forma, é possível afirmar que os estudantes compreendem o uso do preservativo como sinônimo de proteção às ISTs, contudo a resistência ao uso pode ser observada em alguns estudos que apontam uma lacuna entre o conhecimento e a utilizaçáo de preservativo entre os jovens, além de uma série de justificativas para evitarem o uso, como o desconforto e a diminuição da sensibilidade. ${ }^{(15,25-27)}$

A vacinação não exclui as açôes de prevenção e de detecção precoce pelo rastreamento, que busca lesões precursoras e câncer em mulheres assintomáticas. ${ }^{(8)}$ A maioria dos estudantes do presente estudo concordam com essa afirmação, assim como os de pesquisa realizada com estudantes de medicina, na qual 91\% dos participantes concordaram que mesmo vacinadas, é necessário que as mulheres realizem o exame citopatológico. ${ }^{(18)}$

Quanto à aceitabilidade da vacina, a maioria dos participantes respondeu afirmativamente. A mesma pergunta foi feita em outro estudo a profissionais de 
saúde com $81,5 \%$ de afirmaçóes. ${ }^{(13)}$ Entretanto, ainda que os estudantes recomendem a vacina, a adesão à mesma é inferior ao número de pessoas que a recomendam, pois $41,8 \%$ do primeiro ano e $84,1 \%$ do último relataram não terem sido vacinados. As barreiras à aceitação podem estar relacionadas ao medo da dor, receio de desaprovação familiar, a desinformação e os tabus, como por exemplo, achar que a vacinação irá estimular a atividade sexual precoce. ${ }^{(21)}$ Os mitos relacionados ao HPV podem gerar uma supervalorização da vacina, afetando a percepção quanto à significância do vírus e do CCU. ${ }^{(28)}$

Foram pesquisados estudantes de uma única IES pública em enfermagem. Sugere-se que novos estudos abordem estudantes de outras instituiçóes, incluindo as de ensino privado, ampliando os resultados, inclusive comparativos.

\section{Conclusão}

Os resultados encontrados e discutidos revelaram que, apesar de os acadêmicos terem demonstrado conhecimento quanto ao HPV, sua transmissibilidade e relação direta com o CCU, diversas lacunas de conhecimento foram identificadas, como finalidade do exame citopatológico, fatores de risco para infecção pelo HPV e questôes vacinais, como número de doses, riscos e benefícios. Sendo a enfermagem um curso da área da saúde, é esperado que estes alunos como futuros enfermeiros adquiram e disseminem o conhecimento acerca da vacinaçáo contra o HPV e sobre a doença, pois estes devem estar aptos a trabalhar, em seus ambientes laborais, com educação em saúde sobre o HPV.

\section{Colaborações}

Panobianco MS orientou e trabalhou na concepção, pesquisa, metodologia, redação final e aprovação da versão a ser publicada do artigo. Bezerril AV trabalhou na concepção, pesquisa, metodologia e na redação final do artigo; Nunes LC trabalhou na redação final e revisão crítica do artigo; Gozzo TO trabalhou na revisão critíca e redação final do artigo.
Outras autoras: trabalharam na redação final e revisão crítica do artigo.

\section{Referências}

1. World Health Organization (WHO). International Agency for Research on Cancer. Press Release № 250. Affordable vaccines key to scale up HPV vaccination and prevent thousands of avoidable cervical cancers. Geneva: WHO; 2017.

2. Brasil. Ministério da Saúde. Instituto Nacional de Câncer José Alencar Gomes da Silva (INCA). Controle do câncer do colo do útero. Conceito e Magnitude. Rio de Janeiro: INCA; 2020 [citado 2021 Mar 8]. Disponível em: https://www.inca.gov.br/controle-do-cancer-do-colo-do-utero/ conceito-e-magnitude

3. Brasil. Ministério da Saúde. Instituto Nacional de Câncer José Alencar Gomes da Silva (INCA). Tipos de Câncer. Colo do Útero. Rio de Janeiro: INCA; 2018 [citado 2021 Mar 8]. Disponível em: https://www.inca.gov. br/tipos-de-cancer/cancer-do-colo-do-utero

4. Sequera M, Matamoros A, Mendoza-León MJ. Genotipos de VPH y cambios citológicos cervico-uterino en pacientes de una consulta ginecológica privada del Estado Carabobo, Venezuela, Marzo-octubre de 2017. Rev Méd Risaralda. 2020;26(1):28-37.

5. Costa TM, Heráclio S, Amorim MM, Souza PR, Lubambo N, Souza GF. Papilomavírus humano e fatores de risco para adenocarcinoma cervical no estado de Pernambuco, Brasil. Rev Bras Saude Mater Infant. 2019;19(3):641-9.

6. Nadal L, Saad SS, Lopes FG, Joaquim HP, Manzione TD, Manzione CR. Comparison between anal cytology, high-resolution anoscopy and HPV DNA genotyping by polymerase chain reaction in the posttreatment follow-up of condylomata acuminata. Rev Col Bras Cir. 2020;47:e20202543.

7. Brasil. Ministério da Saúde. Instituto Nacional de Câncer José Alencar Gomes da Silva (INCA). Tipos de câncer: Colo do Útero. Detecção e Precoce. Rio de Janeiro: INCA; 2020 [citado 2021 Mar 8]. Disponível em: https://www.inca.gov.br/controle-do-cancer-do-colo-do-utero/ acoes-de-controle/deteccao-precoce

8. Brasil. Ministério da Saúde. Instituto Nacional de Câncer José Alencar Gomes da Silva (INCA). Diretrizes brasileiras para o rastreamento do câncer do colo do útero. Rio de Janeiro: INCA; 2016 [citado 2021 Mar 8]. Disponível em: http://www.citologiaclinica.org.br/site/pdf/ documentos/diretrizes-para-0-rastreamento-do-cancer-do-colo-doutero_2016.pdf

9. Baldissera SS, Rosanelli CL, Donaduzzi DS, Anversa ET. Promoção da saúde e prevenção do câncer do colo uterino: estratégias utilizadas pelos enfermeiros. Res Society Development. 2020;9(9):e504997494.

10. Carneiro CP, Pereira DM, Pereira AT, Santos GA, Moraes FA, Duarte RF. 0 Papel do enfermeiro frente ao câncer de colo uterino. Rev Eletrônica Acervo Saúde. 2020;0(Sup.35):e1362.

11. Brasil. Ministério da Saúde. Secretaria de Vigilância em Saúde. Departamento de Vigilância das Doenças Transmissíveis. Coordenação Geral do Programa Nacional de Imunização. Informe técnico da ampliação da oferta das vacinas papilomavírus humano 6, 11, 16 e 18 (recombinante) - vacina HPV quadrivalente e meningocócica C (conjugada). Brasília (DF): Ministério da Saúde; 2018 [citado 2021 Mar 8]. Disponível em: https://portalarquivos2.saude.gov.br/images/ pdf/2018/marco/14/Informe-T--cnico-HPV-MENINGITE.pdf 
12. Brasil. Ministério da Saúde. Instituto Nacional de Câncer José Alencar Gomes da Silva (INCA). Prevenção do câncer do colo do útero. Rio de Janeiro: INCA; 2018 [citado 2021 Mar 8]. Disponível em: https://www. inca.gov.br/controle-do-cancer-do-colo-do-utero/acoes-de-controle/ prevencao

13. Leite e Sousa PD, Takiuti AD, Baracat EC, Sorpreso IC, Abreu LC. Knowledge and acceptance of HPV vaccine among adolescents, parents and health professionals: construct development for collection and database composition. J Hum Growth Dev. 2018;28(1):58-68.

14. Okamoto CT, Faria AA, Sater AC, Dissenha BV, Stasievski BS. Profile of knowledge on HPV and its prevention among students at a private University in Curitiba. Rev BrasEduc Med. 2016;40(4):611-20.

15. Biselli-Monteiro M, Ferracini AC, Sarian LO, Derchain SFM. Influence of Gender and Undergraduate Course on the Knowledge about HPV and HPV Vaccine, and Vaccination Rate among Students of a Public University. Rev Bras Ginecol Obstet. 2020;42(2):96-105.

16. Hino P, Freitas NC, Onofre PS, Souza KL, Santos JO. Knowledge of undergraduate nursing students about human papillomavirus vaccine. Rev Rene. 2016;17(5):586-92.

17. Medeiros FK, Leite KN, Souza TA, Nunes GS, Sousa KM, César ES. The Nursing Students' Viewpoint Regarding the Papanicolaou Test for Gynecological Diseases Diagnosis. J Res Fundam Care Online. 2019;11(5):1167-72.

18. Silva SL, Vargas AL, Almeida RJ, Saddi VA, Cordeiro JA, Silva AM. Conhecimento dos acadêmicos de medicina acerca do HPV e do câncer de colo uterino. Saúde (Santa Maria). 2017;43(2):125-36.

19. Brasil. Ministério da Saúde. Instituto Nacional de Câncer José Alencar Gomes da Silva (INCA). Estimativa 2020: Incidência de Câncer no Brasil. Rio de Janeiro: INCA; 2019 [citado 2021 Mar 8]. Disponível em: https://www.inca.gov.br/sites/ufu.sti.inca.local/files/media/document/ estimativa-2020-incidencia-de-cancer-no-brasil.pdf

20. Goud EV, Malleedi S, Ramanathan A, Wong GR, Wei EM, Wen YT, et al. Evaluation of human papillomavirus 16 and human papillomavirus
18 in saliva of chronic smokers in Malaysian population: an in vitro observational study. Arch Med Health Sci. 2017;5(1):16-20.

21. Oliveira MS, Sorpreso IC, Zuchelo LT, Silva AT, Gomes JM, Silva BK, et al. Knowledge and acceptability of HPV vaccine among HPV-vaccinated and unvaccinated adolescents at Western Amazon. Rev Assoc Med Bras. 2020;66(8):1062-9.

22. Brasil. Ministério da Saúde. Instituto Nacional de Câncer José Alencar Gomes da Silva (INCA). Vale a pena vacinar, contra o HPV, mulheres que já iniciaram a atividade sexual? Perguntas frequentes. Rio de Janeiro: INCA; 2019 [citado 2021 Mar 8]. Disponível em: https://www. inca.gov.br/perguntas-frequentes/vale-pena-vacinar-contra-0-hpvmulheres-que-ja-iniciaram-atividade-sexual

23. Baggio MA, Berres R, Gregolin BP, Aikes S. Introduction of the School Health Program in the city of Cascavel, Paraná State: report of nurses. Rev Bras Enferm. 2018;71(Suppl 4):1540-7.

24. Ribeiro DK, Vieira MT, Carvalho TR, Pinheiro AP, Jesus RR, Freitas F0, et al. Experiência de estudantes de enfermagem em um projeto de educação em saúde e sexualidade na escola. Rev Guará. 2018;9:8596.

25. Petry S, Padilha MI, Kuhnen AE, Meirelles BH. Knowledge of nursing student on the prevention of sexually transmitted infections. Rev Bras Enferm. 2019;72(5):1145-52.

26. Teixeira RC, Maria ES, Silva FJ, Kietzer KS, Nunes EF, Andrade FS, et al. Uso de preservativos por alunos de cursos de saúde em uma universidade pública. Semina: Ciênc Biol Saúde. 2018;39(1):85-90.

27. Costa MI, Rodrigues RR, Teixeira RM, Paula PH, Luna IT, Pinheiro PN. Adolescents in situations of poverty: resilience and vulnerabilities to sexually transmitted infections. Rev Bras Enferm. 2020;73(Supl.4):e20190242.

28. Wang LD, Lam WW, Fielding R. Determinants of human papillomavirus vaccination uptake among adolescent girls: a theory-based longitudinal study among Hong Kong Chinese parents. Prev Med. 2017;102:2430. 